\title{
O violino violado: 0 entremear das vozes esquecidas das rabecas e de "outros violinos"
}

\author{
Luiz Henrique Fiaminghi (UNICAMP, Campinas) \\ Infiaminghi@yahoo.com.br
}

\begin{abstract}
Resumo. A representação do violino como instrumento musical hegemônico é um fato incontestável se considerarmos sua presença nos mais diversos âmbitos das práticas da música ocidental. As últimas décadas presenciaram, porém, a emergência de algumas vozes dissonantes: as práticas interpretativas historicamente informadas (Historically Informed Performance ou HIP) redescobriram o violino barroco e todo o seu aparato técnico; no Brasil, a rabeca mostrou suas potencialidades, não mais somente nas mãos de ardorosos defensores da cultura popular, mas de músicos em busca de novas sonoridades. Tomando como exemplo a intersecção do popular e erudito contido nas peças para rabeca escritas por José Eduardo Gramani, pretende-se aqui, sobretudo, mais do que apresentar respostas definitivas, abrir novas questões relacionadas ao ensino do violino no mundo contemporâneo, a partir da inserção de instrumentos esquecidos pela história oficial. Neste sentido, reflete alguns dos aspectos defendidos por Walter Benjamin em Sobre o conceito de história, e traz para a pauta das discussões sobre interpretação musical a questão da padronização imposta pela indústria cultural.
\end{abstract}

Palavras-chave: rabecas, violino barroco, práticas interpretativas, HIP (Performance Historicamente Informada).

\section{The fiddled violin: the clamor of forgotten voices from the Brazilian rabecas and "other violins"}

Abstract. The representation of the violin as a hegemonic musical instrument is an undisputed fact, regarding its presence within the widest scope of Western musical performance. The last decades have witnessed, however, the emergency of some dissonant voices: the Historically Informed Performance (HIP) practice has rediscovered the baroque violin and all its technical apparatus; the Brazilian fiddle rabeca claimed to be heard through its own voice, despite the neglectful approach from the mainstream scholars and musicians. Departing from the intersection between popular and erudite culture that characterizes most of Brazilian José Eduardo Gramani's music written for rabeca, this article raises reflections about violin teaching in a multi-cultural society, according to the concepts of Walter Benjamin's Über den Begriff der Geshichte. It discusses the standardization of performance practice imposed by the cultural industry.

Keywords: Brazilian fiddle, Baroque violin, performance practices, HIP (Historically Informed Performance)

\section{1 - 0 Império do violino}

Desde o seu aparecimento na cena musical em finais do séc. XVI, o violino assumiu papel central na prática instrumental européia. Suas capacidades intrínsecas de articulação do som e a maleabilidade de potência e extensão melódica, que varia da imitação do murmúrio das flautas à exuberância dos trompetes, qualificaramno a rivalizar com o canto na arte das diminuições, do virtuosismo e da representação retórica instrumental com a função catártica de magnetização das audiências. Como herdeiro de outras famílias de instrumentos de corda com arco que lhe deram origem (viola bastarda; lira da braccio; rabeca medieval), estava predestinado a imperar soberanamente nos séculos seguintes, adaptandose como nenhum outro instrumento aos diversos estilos musicais que surgiram ao longo de sua história.

0 séc. $X I X$, na verdade, coroou esta história, podendo ser considerado o "século de ouro do violino". Todos os compositores desta época, exceto os que escreveram exclusivamente para a ópera, dedicaram ao violino, pelo menos, um grande concerto. Estas composições acabariam por se cristalizar na programação habitual das salas de concerto, constituindo um representativo repertório do periodo romântico.

As mudanças ocorridas no ensino do violino para adaptálo à linguagem romântica, têm como referência o ano de 1802. Nesse ano é publicado em Paris o "Méthode de violon par Baillot, Rode et Kreutzer", três eminentes professores de violino do Conservatório de Paris, que escreveram este método sob a égide do novo ensino, estabelecendo as bases do ensino moderno do violino que perduram até os dias de hoje. Tecnicamente falando, tratava-se de aparelhar o violinista para a prática de um novo estilo de música, que priorizava a grande linha melódica e a igualdade das arcadas em detrimento da clareza de articulação de pequenos motivos e da variedade 
nas inflexões de arco. 0 efeito retórico alcançado pelo instrumento que "falava" e "articulava" o texto musical daria lugar, nesta nova técnica, à "pintura" e ao legato de longas frases musicais. Harnoncourt aborda este assunto muito precisamente:

\begin{abstract}
"Tratava-se de substituir a retórica pela pintura. Foi assim que se desenvolveram o 'sostenuto', a grande linha, o 'legato' moderno. Evidentemente a grande linha melódica já existia antes, mas constituída perceptivelmente de pequenas células reunidas num bloco. Esta revolução na educação musical foi de tal forma radicalmente levada adiante que, em algumas décadas por toda a Europa, os músicos passaram a ser formados pelo sistema de conservatório". (HARNONCOURT, 1990, p.30)
\end{abstract}

Não é de se estranhar, portanto, que a primeira mudança técnica efetuada foi em relação ao arco. Embora o arco modelo Tourte, que é basicamente o mesmo que se utiliza até hoje, fosse conhecido desde a segunda metade do séc. XVIII, ele passou a ser adotado como o arco ideal para reprodução da nova sonoridade somente a partir das mudanças estéticas advindas com o romantismo. Sua capacidade de sustentação e de igualdade do som, proporcionadas pelo maior equilíbrio de peso entre o talão e a ponta, e pela curvatura convexa do arco, o habilitaram a substituir os arcos antigos, provenientes de vários modelos, utilizados desde o início do séc. XVII. Estes arcos, de fato, eram mais apropriados para o aproveitamento da articulação e da ressonância natural do instrumento, projetando, entretanto, menor volume de som que os arcos modelo Tourte. Sua característica principal era a leveza e a agilidade necessárias para realização das figurações virtuosísticas barrocas, que envolvem constantes mudanças de corda, tipo "bariolage".

Um ponto de distinção importante entre os dois tipos de arco, é que os arcos barrocos mantiveram em suas características rastros de sua origem nos sécs. XVI e XVII, quando eram utilizados para o acompanhamento de danças. Isto implicou na manutenção de uma hierarquia na acentuação rítmica realizada pelo arco, como fundamento para boa execução musical regrada pela retórica dos gestos (na dança) e da oratória (na música), exatamente o oposto da igualdade proposta pela nova escola. Esta hierarquia é descrita claramente em inúmeros tratados barrocos. Neste sentido, os tratados Florilegium I e // de Georg Muffat, publicados respectivamente em 1695 e 1698, em Passau, são esclarecedores. Muffat foi o principal propagador do estilo francês de J. B. Lully fora da França, descrevendo minuciosamente o uso do arco para a correta execução musical deste estilo:

"[0 uso do arco] indica a métrica da dança tão exatamente que pode-se reconhecerimediatamente o tipo da peça, e sentir o impulso da dança nos pés e no coração...Para o estilo de Lully, as notas mais importantes da métrica musical, são especialmente aquelas que começam o compasso e terminam uma cadência, evidenciando o movimento da dança, devendo ser tocadas da mesma maneira." (MUFFAT, 1695, apud WILSON, 2001, p. 104)

A importância da hierarquia nas inflexões das arcadas se esclarece no comentário de David Wilson:
"De fato, todas as regras de arcada descritas por Muffat são designadas para ressaltar as inflexões fortes e fracas da música, mostrando assim auditivamente o movimento de qualquer dança que estiver sendo tocada. Como o arco para baixo significa acentuação e o arco para cima o reflexo fraco deste impulso, no caso da utilização de um arco barroco, as convenções sobre arcadas resultam em convenções sobre inflexões fortes ou fracas, baseadas nas partes fortes ou fracas do compasso, ou como Muffat diz, nos movimentos das danças". (WILSON, 2001, p.104)

As técnicas que tiveram sua origem na prática popular, e eram remanescentes ou sobreviventes na música instrumental por intermédio das danças que, como vimos através do exemplo de Muffat, ainda eram vivas e mantidas nas práticas interpretativas barrocas, foram abandonadas por completo na estética romântica. Um bom indício do seqüestro destas práticas no romantismo é a ausência de treinamento técnico específico para realização de tais nuances de acentuação, nos métodos nascidos a partir do advento do Conservatório. Mesmo em países como a Inglaterra, onde havia uma forte tradição do emprego do violino no âmbito popular, através das danças originárias de reels (rondós) irlandeses e escoceses, e ao mesmo tempo, era um grande centro editorial de partituras e métodos, além de abrigar vários dos mais importantes músicos da época, o interesse em aproveitar a sintaxe do dialeto popular e incorporá-la ao léxico disponível aos instrumentistas eruditos era inexistente.

0 caso das strathspeys escocesas é exemplar neste sentido. 0 violino foi introduzido nas Highlands (terras altas) escocesas nos finais do séc. XVII pelos lordes escoceses interessados em anglicizar os costumes do povo escocês, como decorrência da união entre os dois países. 0 violino não só foi aceito, como se tornou o principal instrumento da música folclórica escocesa, substituindo as tradicionais gaitas de fole na prática de danças estilizadas, como é o caso das strathspeys. Este estilo de dança instrumental, cujo maior representante foi o violinista autodidata escocês Niel Gow, foi especialmente cultivado nos círculos urbanos londrinos na passagem do séc. XVIII para o XIX. Gow alcançou enorme reputação como intérprete e compositor, como atestam suas coletâneas editadas no período, tendo o seu estilo de tocar chamado a atenção de cronistas da época. Segundo Carlin:

\footnotetext{
"As coletâneas de músicas de Gow foram editadas entre 1784 até 1822. São raras não somente pela abrangência da música anotada como também pela qualidade dos arranjos e do cuidado com que a música foi tipografada. Niel Gow foi aclamado em sua época como o pioneiro do 'up-driven bow', um estilo de utilização do arco para a acentuação rítmica característica da 'strathspey'... que é conhecido como 'Scotch snap'".(CARLIN, 1986, p.14)
}

Apesar de haver registros significativos em relação à prática das strathspeys, e da particularidade do "updriven bow" como golpe de arco, este "dialeto" não foi considerado relevante a ponto de ser incorporado à sintaxe moderna do violino e conseqüentemente, aos métodos para formação de violinistas. Sobreviveu e chegou até nós pela transmissão oral de sua prática. 


\section{2 - Em busca da rabeca perdida: Mário de Andrade e o papel dos mediadores}

Dentro do panorama descrito acima, é natural que nos depararemos com a completa ausência de registros acerca das práticas musicais que envolvem a rabeca no período romântico e também nos subseqüentes. 0 pensamento monolítico em relação aos instrumentos da "grande música" ou da "música séria" atravessou as fronteiras do romantismo, seguindo saudável e seguro no séc. XX adentro. Exemplo disto é a aparente contradição que Mário de Andrade expressa ao referir-se à rabeca. Aparente porque, não há contradição alguma se considerarmos a inserção de Mário como pioneiro do trabalho musicológico e etnomusicológico no Brasil. Suas pesquisas, empreendidas entre 1928 e 1938, e publicadas postumamente por Oneyda Alvarenga, não poderiam àquela altura, ser realizadas de outra forma, que não pelo ímpeto "romântico" do registro e sem as ferramentas utilizadas posteriormente pela moderna etnomusicologia.

Apesar da abrangência da obra de Mario de Andrade, em relação à rabeca, seus postulados acrescentam apenas algumas poucas linhas acerca da origem do instrumento, evitando qualquer comentário sobre suas práticas e aspectos técnicos. A despeito de encontrá-la à beira do desaparecimento, Mario de Andrade não dedicou a ela nenhum registro mais aprofundado, que the tirasse a conotação de mero "violino primitivo" ou "versão popular do violino". 0 mesmo parâmetro não foi adotado, por exemplo, quando Mario registrou, com um encantamento contagiante, o côco como gênero musical e a musicalidade do cantadorl embolador Chico Antonio, nas viagens do "Turista Aprendiz", em 1928. Neste caso, o parâmetro adotado não foi o canto lírico, mas, pelo contrário, as potencialidades que aquele gênero ancestral de canto poético, improvisado e visceral, poderia contribuir para a música brasileira, conforme os ideais estéticos que Mario defendia.

Para entendermos melhor este fenômeno devemos recorrer a outras fontes e contextualizar o momento em que Mario de Andrade empreendeu suas pesquisas e a inserção da rabeca neste contexto cultural. Neste sentido, Peter Burke, em Cultura Popular na Idade Moderna, oferece pistas sobre como abordar metodologicamente os elementos faltantes na composição de uma história cultural, e aponta alguns aspectos fundamentais no papel dos mediadores, ou seja, os filtros culturais que atuam entre o objeto estudado e nós:

"Estudar a história do comportamento dos iletrados é necessariamente enxergá-la com dois pares de olhos estranhos a elas; os nossos e os dos autores dos documentos que servem de mediação entre nós e as pessoas comuns que estamos tentando alcançar". (BURKE, 1995, p.94)

Portanto, o silêncio de Mário de Andrade acerca das rabecas é tão importante quanto o seu entusiasmo em relação a Chico Antônio para determinar mudanças de atitudes dos mediadores entre cultura popular e erudita. Neste sentido, sua reação positiva face ao encontro com uma poesia improvisada, cantada visceralmente e contrastante com a polidez e o tecnicismo dos cantores líricos, pode ser vista como uma atitude vinculada ainda aos conceitos do idealismo romântico que procuravam encontrar na arte primitiva o sinônimo de pureza. Ecos tardios da teoria de Herder, tecida há mais de século e meio e que via no popular a purificação do erudito. A despeito de navegar guiado pela bússola do modernismo, Mario estava ainda submerso nas ondas agitadas em solo alemão pelo idealismo romântico, que chegavam a nossas praias após longo percurso de 150 anos, mas ainda vigorosas o suficiente para marear o arguto observador da Nau Catarineta.

Apesar de, dentro da estética romântica, os artistas abrirem as portas da criação para receber os fluxos advindos das camadas inferiores da sociedade, e receber desta a matéria básica a ser modelada, a cultura popular permaneceu no lugar que sempre ocupou, ou seja, na posição inferior de fonte fornecedora de matéria prima para a arte erudita. Analogamente, esta posição é a mesma representada no jogo político entre metrópole e colônia, que no caso do nosso hemisfério, perdurou, com maior ou menor intensidade, de acordo com a balança das políticas internacionais, até os dias de hoje.

Dentro da visão romântica e do nacionalismo, não havia, portanto, espaço para os instrumentos populares fora do âmbito folclórico e tampouco para os músicos provenientes destas culturas. 0 mesmo poder-se-ia dizer em relação às artes plásticas e à dança: a adoção de temas pastoris ou políticos na pintura e na escultura, sem dúvida ampliou o leque temático retratado, deixando intocada, porém, a relação privilegiada da Arte vis-à-vis ao artesanato; 0 Ballet, quando incluiu algum tema folclórico ou regional, o fez sem deixar de excluir, no entanto, qualquer vestígio de movimento corporal não originário das academias, e que fizesse referência à terra batida das aldeias.

Sobre as implicações nacionalistas contidas no "resgate" das tradições populares, Canclini mostra que a interação entre popular e erudito, cujo grau mais próximo do romantismo seria a posição sectarista do colecionador de "espécies raras de cultura", condiciona o próprio ato do registro:

\footnotetext{
"Apenas os investigadores filiados ao historicismo idealista se interessam por entender as tradições em um âmbito mais amplo, mas as reduzem a testemunhos de uma memória que supõem útil para fortalecer a continuidade histórica e a identidade contemporânea... No final das contas, os românticos se tornam cúmplices dos ilustrados. Ao decidir que a especificidade da cultura popular reside em sua fidelidade ao passado rural, tornam-se cegos às mudanças que a redefiniam nas sociedades industriais e urbanas. Ao atribuir-lhe uma autonomia imaginada, suprimem a possibilidade de explicar o popular pelas interações que tem com a nova cultura hegemônica. O povo é 'resgatado', mas não conhecido". (CANCLINI, 2003, p.210)
}

Pela ótica romântica que forneceu as regras do jogo da hegemonia cultural dos instrumentos musicais, especificamente do violino em relação à rabeca, o postulado acima se traduziria da seguinte maneira: as manifestações 
populares e seus respectivos instrumentos musicais deveriam ser resgatados e incorporados ao acervo dos museus e coletâneas assim como os ossos dos nossos antepassados são classificados nos sítios arqueológicos. 0 único interesse seria registrar a história para justificar o presente, e não conhecer o passado para transformar o presente.

\section{3 - A história oficial e a (des)continuidade na transmissão da técnica violinística}

As considerações de Burke e de Canclini alertam para questões fundamentais quando se trata de desvelar traços culturais absorvidos ou obscurecidos por uma cultura hegemônica, e ao mesmo tempo, oferece subsídios para aqueles que desejam ir além da história oficial. Neste sentido, seus pensamentos alinham-se à visão de filosofia da história defendidos por W. Benjamin. A partir de suas teses "Sobre o conceito de história", outra face da história dos oprimidos se revela. Segundo J. M. Gagnebin:

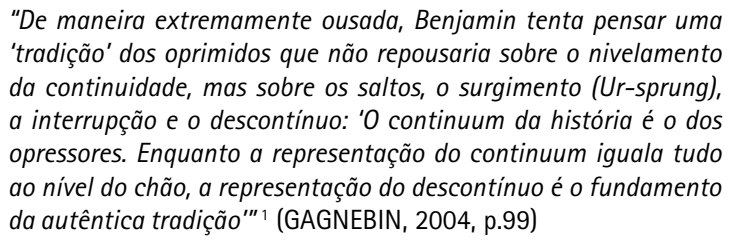

"De maneira extremamente ousada, Benjamin tenta pensar uma 'tradição' dos oprimidos que não repousaria sobre o nivelamento da continuidade, mas sobre os saltos, o surgimento (Ur-sprung), a interrupção e o descontínuo: ' 0 continuum da história é o dos opressores. Enquanto a representação do continuum iguala tudo ao nível do chão, a representação do descontínuo é o fundamento da autêntica tradição ${ }^{\prime \prime \prime} 1$ (GAGNEBIN, 2004, p.99)

A continuidade na transmissão dos conhecimentos, no nosso caso, da técnica violinística, seria, dentro deste ponto de vista, um obstáculo à emergência de outros valores, ou outros prismas para interpretação musical. As quebras, os buracos escuros, a dúvida, e a incoerência, podem, por sua vez, assumir uma função de ruptura do já conhecido e esperado, agindo como elementos catalisadores do questionamento perante uma verdade inquestionável. Isto é válido tanto para os procedimentos esquecidos de como interpretar música barroca com instrumentos de época, especificamente o violino barroco, quanto para incorporar instrumentos "sem história", como a rabeca.

0 encontro da rabeca com o violino tem muito a acrescentar em relação às quebras de procedimentos herdados da tradição e utilizados irrefletidamente para interpretação musical. Coloca-se aqui uma questão fundamental que enfoca este encontro pela ótica da sobreposição e não de oposição de linguagens. Transparências que não apagam as figuras cobertas pela nova camada de tinta, mas que somam uma nova cor a cada pincelada. A nova cor que não é imposta por oposição causada pela cobertura de uma espessa camada de tinta, mas que emerge inesperada, movida pelas vibrações da luminosidade de ambas as cores. Uso propositalmente a analogia pictórica, pois trata-se em última instância, de uma volta aos timbres, das particularidades de cada instrumento, e principalmente da não uniformização.

0 movimento em direção ao encontro de instrumentos de corda fora do mainstream musical, seja a rabeca ou o violino barroco, passa, portanto, por caminhos semelhantes. Como movimento de reação ao modernismo, que esticou o tecido da linguagem musical a ponto de causar o rompimento de comunicação com a audiência e como reencontro do antigo e do tradicional através de uma ótica contemporânea que busca ser a antítese do idealismo romântico, conforme imaginava Herder em sua incessante busca pela pureza do não polido. Também como reação ao "oficial" e conseqüentemente ao convencional. Ser diferente não é mais perigoso, mas passou a ser visto como qualidade por si mesma.

Para trilhar esses caminhos, o intérprete deve apoiar-se em algum fundamento. W. Benjamin oferece, em sua teoria do "recobrimento dos momentos revolucionários do curso da história" uma instigante posição para validar os buracos deixados pela história oficial, a história dos vencedores, que bem poderia servir ao especulador interessado em justificar suas opções pelos elos perdidos da cadeia evolutiva dos instrumentos musicais. Segundo Gagnebin, citando W. Benjamin:

\begin{abstract}
"A história habitual é, de fato, a 'comemoração' das façanhas dos vencedores, ela é a 'apologia' que tende a 'recobrir os momentos revolucionários do curso da história.' ${ }^{2}$ A essa narrativa cumulativa e complacente ele opõe, nos dois fragmentos, a necessidade de ater-se a tudo o que poderia interromper essa aparente coerência: 'A ela [isto é, à habitual representação da história ou à apologia] escapam os lugares nos quais a transmissão se interrompe e, com isso, suas asperezas e suas arestas que oferecem uma escora àquele que quer ir além dela'"'3
\end{abstract}

"Parafraseando essas linhas, podemos afirmar que aquele que quer ir além dessa tradição dos vencedores ('der über sie hinausgehen will') deve saber agarrar-se a essas asperezas (Schroffen), a essas arestas (Zachen) que Ihe oferecem tantas escoras ou pontos de apoio ('die dem einen Halt bieten') na sua luta contra o fluxo nivelador da história oficial que, justamente, deixa escapar esses 'lugares nos quais a tradição/transmissão se interrompe' ('Ihr entgehen die Stellen, an denen die Überlieferung abbricht)". (GAGNEBIN, 2004, p.100)

Desta maneira seria inútil procurarmos encontrar valores essenciais da diversidade musical na prática violinística do séc. XIX, em especial nos métodos de violino como os citados anteriormente. De fato, estes métodos visaram somente a manutenção da continuidade da transmissão de conhecimentos e do treinamento exclusivo para a interpretação de um único estilo musical, não voltando suas atenções para nenhuma outra prática a não ser aquelas pertencentes à "grande música". Considerando que havia paralelamente extensos registros sobre as práticas violinísticas fora da tradição formada pelo romantismo, como por exemplo, os inúmeros tratados barrocos dedicados ao violino, e mesmo os provenientes da tradição popular, como as coletâneas de música violinistica de Niel Gow, percebe-se a unilateralidade com que o ensino gerado pelo Conservatório se impôs.

A saída encontrada dentro de uma ótica pós-moderna foi a adoção dos instrumentos musicais periféricos, alijados do processo interpretativo, como "escoras", ou de acordo com Gagnebin, como "pontos de apoio" para a pesquisa, e, a partir deles, permitir a construção de uma técnica de performance que os incorporassem à práxis musical. 


\section{4 - 0 Inferno de Orfeu: a rabeca como desvio do método e o exemplo de José E. Gramani}

A herança pedagógica deixada pelo romantismo, via conservatório, trilhou um caminho oposto, adotando uma técnica generalizada pronta e perfeita, o que, obrigatoriamente, condicionou a aquisição técnica e a realização musical a uma única forma de conhecimento. Harnoncourt aponta para os perigos de uma técnica generalizada como base para formação musical de forma contundente:

\begin{abstract}
"Estritamente falando, o músico atual recebe uma formação, cujo método é muito pouco compreendido, tanto pelo seu professor, quanto por ele mesmo. Ele aprende os sistemas de Baillot e de Kreutzer [em referência aos primeiros métodos de violino editados no Conservatório de Paris], que foram concebidos para seus contemporâneos, e os aplica à música de épocas e estilos inteiramente diversos. Aparentemente, sem qualquer reflexão, são utilizados na educação musical atual princípios teóricos que há cento e oitenta anos faziam sentido, mas que, hoje em dia, não se compreendem mais...Um violinista com a mais perfeita técnica de Paganini e de Kreutzer não deveria acreditar-se 'dono' das ferramentas necessárias para executar Bach ou Mozart. Para tal, ele precisaria conhecer as condições técnicas e o sentido da música 'eloqüente' do séc. XVIII" (HARNONCOURT, 1990, p.31)
\end{abstract}

Seguindo a receita utilizada em todas as ditaduras, uma formação musical ancorada em tamanha estandardização técnica, seria, analogamente, o mesmo tipo de violência que oferecer aos estudantes de humanidades uma biblioteca formada unicamente por livros de uma determinada corrente estética ou filosófica. Longe de ser uma exclusividade da didática do violino, e ser ainda de uma atualidade preocupante, a padronização do ensino musical reflete um universo maior, formado pelas mudanças em todas as esferas da sociedade, decorrentes da urbanização e da industrialização aceleradas como conseqüências da revolução industrial. A individualidade artística, que é uma das características do romantismo, transfigura-se em individualidade ilusória que resulta da imposição de receitas ditadas por uma indústria cultural ávida de produtos de uso imediato e rentáveis. Em suas definitivas análises sobre as mazelas da indústria cultural do pós-guerra, e em caráter profético, Adorno alerta para as armadilhas da padronização cultural, muito antes do neo-liberalismo se tornar pauta dos jornais:
"Na indústria cultural o indivíduo é ilusório não só pela estandardização das técnicas de produção. Ele só é tolerado à medida que sua identidade sem reservas com o universal permanece fora de contestação. Da improvisação regulada do jazz até a personalidade cinematográfica original, que deve ter um topete caído sobre os olhos para ser reconhecida como tal, domina a pseudo-individualidade. 0 individual se reduz à capacidade que tem o universal de assinalar o acidental com uma marca tão indelével a ponto de torná-lo de imediato identificável" (ADORNO, 2004, p.55-56)

"Toda voz de tenor soa exatamente como um disco de Caruso, e os rostos das garotas do Texas naturalmente se assemelham aos modelos segundo os quais seriam classificadas em Hollywood. A reprodução mecânica do belo, que a exaltação reacionária da 'cultura', com a sua idolatria sistemática da individualidade, favorece tanto mais fatalmente, não deixa nenhum lugar para a idolatria inconsciente a que o belo estava ligado" (ADORNO, 2004, p.35)

A Arte como meio de abrir as portas iniciáticas de mundos incógnitos, e a música como seu meio mais fluido e irracional, remete diretamente à mitologia de Orfeu. Flautas mágicas e liras da braccio permeiam os véus que encobrem "a idolatria inconsciente a que o belo estava ligado". Impossivel não imaginar as representações renascentistas de Orfeu e sua lira, a cantar despreocupadamente. 0 inferno de Orfeu é "a reprodução mecânica do belo", a reprodução banal de sua Arte, uma dentre as milhares de cópias do sorriso da Monalisa. Não é por acaso que um dos aspectos que mais chamou a atenção de J. E. Gramani em relação às rabecas foi a não padronização destes instrumentos. Cada rabequeiro, uma rabeca. Cada rabeca, uma música. Cada música, uma interpretação. 0 inesperado som da rabeca ${ }^{4}$ é uma ode a não-padronização, o que estava perfeitamente de acordo com uma percepção do mundo voltada aos sub-textos contidos nos discursos oficiais. A rabeca como desvio, violino violado que não violenta a tradição, e tampouco busca a permanência de alguma tradição. Apenas expressa o protesto de um artista cuja voz retoma o canto perdido de um Orfeu ancestral e para isso, tanto mais efetivo é o seu canto, quanto mais longe do verniz está a porosidade de sua arte. Técnica sim, mas não como congelamento de algum procedimento mecânico. 


\section{Referências}

ADORNO, Theodor W. (2004) - Indústria Cultural e Sociedade. S. Paulo, Ed. Paz e Terra S/A. (1998) - "Em defesa de Bach contra seus admiradores" (1951) in Prismas, S. Paulo, Ed. Ática.

(1990) - Prisms, Cambridge, Massachusetts, The MIT Press.

ANDRADE, Mário de (1982) - Danças Dramáticas do Brasil. Belo Horizonte, Ed. Itatiaia. (1989) - Dicionário Musical Brasileiro. Belo Horizonte, Ed. Itatiaia.

BOYDEN, David D. (1965) - The History of Violin Playing from its Origins to 1761. Oxford, Oxford University Press.

BURKE, Peter (1995) - Cultura Popular na Idade Moderna, S. Paulo.Ed. Schwarcz Ltda,

BUT, John (2002) - Playing with History - The Historical Approach to Musical Perormance. Cambridge, UK, Cambridge University Press.

CANDIDO, Antonio (1964) - Os parceiros do Rio Bonito. S. Paulo, Editora 34.

CARLIN, Richard - THE "GOW COLLECTION" OF SCOTISH DANCE MUSIC - Compiled \&t Edited by Richard Carlin - Oak publications, New York, 1986.

COLI, Jorge - Música Final - Mário de Andrade e sua coluna jornalística Mundo musical. Campinas, editora da Unicamp.

DUARTE, Rodrigo (2005) - Teoria crítica da indústria cultural. Belo Horizonte, Editora UFMG.

GAGNEBIN, J.M.(2004) - História e narração em W. Benjamin. S. Paulo , Perspectiva.

(2006) - Lembrar escrever esquecer, S. Paulo, Editora 34

s/d - apostila de aula: Walter Benjamin, Observações sobre "Baudelaire", Gesammelte Schriften I-3, pp. 1160/61.

Trad. Caseira de JMG.

GARCÍA CANCLINI, Nestor (2003) - Culturas Hibridas. São Paulo, editora USP.

GRAMANI, José E.(2002); org. Daniella Gramani - Rabeca, o som inesperado. Curitiba, edição independente.

GEMINIANI, Francesco (1751) - The Art of Playing on the Violin, edição fac-simili, prefácio e introdução de David Boyden (1970), Oxford, Oxford University Press.

HARNONCOURT, Nikolaus (1990) - O discurso dos sons. RJ, Jorge Zahar Ed.

KERMAN, Joseph (1987) - Musicologia, Martins Fontes Ed. , São Paulo.

LÖWY, Michael (2005) - Walter Benjamin: aviso de incêndio, Boitempo Ed. São Paulo.

MURPHY, John P. (1997) "The rabeca and its music, old and new, in Pernambuco, Brazil". Latin American Review. University of Texas Press, Austin.

NÓBREGA, Ana C. P. (2000) - A Rabeca no Cavalo Marinho de Baieux. João Pessoa, Editora Universitária.

TARUSKIN, R. (1995) - Text and Act. Essays on Music and Performance. New York/Oxford: Oxford University.

WILSON, David K. (2001) -Georg Muffat on Performance Practice - Florilegium Primum, Florilegium Secundum, edição e tradução, Indiana University Press, Bloomington, Indianápolis.

\section{Notas}

1 BENJAMIN, Walter (1974) - Gesammelte Schiften, p.236, Frankfurt am Main, Suhrkamp. Trad. J. M. Gagnebin.

2 BENJAMIN, Walter - Passagen-Werk, Ges. Schr. V, pl 592, fragmento N9a,5.

3 BENJAMIN, Walter - Ges. Schr. 1-3, p.1242 (trad. J.M.G.)

4 Referência à "Rabeca, o som inesperado" (2002), editora independente, Curitiba, publicação póstuma de J. E. Gramani sobre a pesquisa realizada entre 1995 e 1997, com apoio da FAPESP, abordando o universo musical de quatro construtores de rabecas e rabequeiros brasileiros. Orgização Daniella Gramani.

Luiz Henrique Fiaminghi estudou violino com Paulo Bosisio e Ayrton Pinto (UNESP/SP). É bacharel em composição e regência pela UNICAMP/SP. Foi violinista da Orquestra Sinfônica Municipal de Campinas. Em 1987, obteve bolsa de especialização do CNPq para estudar violino barroco e interpretação de música barroca na Holanda, tendo estudado nos Conservatórios de Rotterdam (profa. Marie Leonhardt) e de Utrecht (profa. Alda Stuurop). Em 1995 escreveu a monografia "Violino e Retórica" com orientação do Prof. Dr. João A. Hansen no curso de especialização em "Arte e Cultura Barroca" da UFOP, MG. De 1993 à 1995, foi professor de violino na UDESC. Fundador do Trio Carcoarco. Desde 1996 é membro do grupo Anima, com o qual gravou e produziu 5 CD's, e realizou diversas turnês no Brasil e no exterior, tendo recebido os prêmios "APCA" (1998) e "Carlos Gomes" (2000), como melhor grupo de música de câmara. Concluiu doutorado em música na UNICAMP com a tese: "O Inferno de Orfeu: rabeca, hibridismo e desvio do método nas práticas interpretativas contemporâneas - tradição e inovação em José Eduardo Gramani", orientado pelo Prof. Dr. Esdras Rodrigues. 